\title{
Policultural Competence Development in the System of Foreign Language Education
}

\author{
Liudmila Khalyapina ${ }^{1}$, Galina Elizarova ${ }^{2}$ \\ Kemerovo State University ${ }^{1}$, Herzen State Pedagogical University ${ }^{2}$, Russia \\ lhalapina@bk.ru,elizg@herzen.spb.ru
}

\begin{abstract}
Polycultural competence is regarded as a new perspective in the theory and methods of teaching foreign languages based on the cognitive linguistic and focused on the fact that teaching foreign languages is not only a language code acquisition. An important component of teaching is the conceptual world picture of native speakers belonging to different cultures. To understand their similarities and differences is necessary for positive interaction in the situation of multicultural globalizing world.
\end{abstract}

\section{Introduction}

In order to prepare future linguists for their effective professional activity in the globalizing polycultural world so that they could help people from different countries of the world to communicate and to cooperate with each other, we have created a new approach to the process of language education. The objective of our research is to create a new methodological system for developing a polycultural competence in the system of a foreign language education.

The idea of our approach is based on a new goal in this system: to develop a new type of competence - polycultural - including polylinguistic, polyconceptual and communicational-technological competences. All these competences were defined in the process of investigation of the demands of new global society.

Theoretical and conceptual framework lies in the sphere of three scientific branches: 1) theory of teaching foreign languages; 2) studies in the field of intercultural communication; 3) studies in the field of cognitive linguistics.

The main achievements in the theory of teaching foreign languages of present-day science are connected with the idea of coherent process of language and culture acquisition. But the fact is that all these theories touch upon only one language and one culture the language of which is to be taught. For the multicultural world it is not enough.

The studies in the field of intercultural communication are very important for our research from the point of view of understanding differences and similarities between representatives of different cultures. Investigations of universal, ethno-cultural, socio-cultural and individual-cultural concepts and values form a basis for productive intercultural interaction. One more aspect of intercultural communication deals with the communication in the Internet. We are sure that this virtual world is really multicultural and it should be widely investigated and included into our future system of foreign language teacher training. The studies of the Internet language and communicative technologies were in the sphere of our attention [5].

As for the cognitive linguistics, it should be pointed out that studies in this science are important for us so that to investigate the technology of penetrating into the conceptual sphere of native speakers (analyzing dictionaries, texts and discourses from the Internet) for the purpose of their better understanding. We haven not found these very important achievements of cognitive linguistics in the system of teacher education.

Having analyzed all these factors we have come to the conclusion that it is necessary to create a new approach to the foreign language education. We suggest that the main professional competence should be polycultural and its structure could be the following: 1) polylinguistic competence (knowing of several foreign languages and how to teach them); 2) polyconceptual competence (having the skills to fulfill a conceptual analysis and knowing how to teach this analysis); 3) technological communicative competence (knowing different communicative programs in the Internet and having skills to use them and to teach them). Inside these groups of competences particular system of knowledge and skills were worked out, then special topics and themes were chosen, special exercises suggested.

Further on, we have created a new methodological system of language education, which includes principles, material based on the Internet resources, technologies.

\section{Polycultural competence: the development of its model}

The research in the sphere of intercultural and interpersonal communication, which included the works of such well-known specialists as M.J. Bennett [1], M. W. Lasting and J. Koester [2] and 
many others, helped us to come up to the idea that interdisciplinary investigation should be fulfilled for the purpose of developing a model for polycultural competence which is required in the global society. The fact is that many scientists agreed in the conclusion that the main reason of misunderstanding between people belonging to different cultures is not in the sphere of language (it is not difficult to overcome this problem), but in the sphere of mentality, conceptual picture of the world. The problem of this investigation lied within such arias as intercultural communication, linguistic education, sociology, psychology.

Sociology studies of globalization as social theory and global culture and of multiculturalism as its result have proved the idea of the importance of developing new group of competences in the new generation of foreign language teachers. They should know how to build bridges with the representatives of various countries and cultures, but not only with the only foreign country the language of which they learn. The world itself is becoming polycultural. Consequently it is not enough to teach students to understand only one culture.

Intercultural communication and linguistic education (especially cognitive linguistics) studies proved the idea of including the theory and practice of conceptual analysis into the system of teacher training so that they could be taught the procedure of analyzing different language material [3]. This type of the competence we have called polyconceptual. The knowledge and skills which are included into it are connected with conceptual analysis technique on three levels of investigation: word etymology, dictionary analysis (nuclear components), context analysis (interpretation components). As far as in the system of conceptual spheres there exist four of them [4] it was decided to follow this subdivision and to develop four types of conceptual competences: in universal, ethno-cultural, socio-cultural and individual concepts. One of the main goals here was to teach student understand that universal concepts only partially have common features in different cultures, in many aspects their interpretation in different cultures is different.

Linguistic education and sociology studies in the field of communication in multicultural society were accepted by us as the ground for one more competence in a student teacher - polylinguistic. Two approaches are developed here: either to learn English as the language for intercultural communication or to learn several foreign languages (which is more preferable).

Our own investigation of hundreds of Internet recourses (web-sites, forums, chat-conferences), containing huge amount of cultural information of different level made us understand the necessity of including communicational-technological type of competence into our model. Nowadays our intercultural and polycultural communication in the greater part takes place in the virtual reality, in the Internet. Knowing the rules, language, strategies for this type of communication is important for a modern language teacher.

\section{Methodological system for developing a polycultural competence}

For developing of all those components in the model of polycultural competence we have designed a special implementation system, which included such parts as principles, language material, topics, technology.

It is important to mention that the topics were formulated by the students according to their own interests, only after that the concept for investigation was chosen from inside the topic. For example, in the topic "How to create a happy family" the students have investigated the concept "family, values of modern family" in Russian, American and British cultures inside such subtopics as:

- "What is the role of family traditions?"

- "Fathers are also important".

- "Your husband's mother: your friend or your enemy?"

- "The importance of belonging to one and the same religion in one family".

- "Bringing up a biracial child".

The next topic was called "Subcultures in modern life". The students analyzed the concept "subcultures" in different countries. The subtopics suggested by the students were the following:

- "How to avoid misunderstanding between parents and children belonging to subcultures?"

- "Can youth subcultures be dangerous for the society?"

- "Goths. Breaking down the stereotypes".

- "Emo. What can parents do?"

Among some other topics and concepts chosen by the students for investigation were the following. "Changing attitude to bad habits" the concept "bad habits" was analyzed in different cultures; in the topic "The role of money in our life" the concept "money"; in the topic "Surrogacy: is it the way out?" the concepts "maternity" and "marriage" were investigated.

Speaking about technological part of this system it's possible to name special system of exercises created for this purpose:

- group 1: for developing communicational technological competence;

- group 2: for developing polylinguistic competence;

- group 3: for developing polyconceptual competence. 
In order to integrate all the necessary material in one and the same place we have designed a personal web-page, where all the theoretical information about different types of Internet communication, about linguistic peculiarities of the Internet is included [5]. The advantage of the professor's personal web-page for the given course is in the opportunity for the students to open any hyper text which they need as far as their collection on the webpage is very big. It contains connections with edictionaries, web-sites and special texts, forums, chat-groups.

\section{Polycultural competence: evaluation of its development}

General methodology is based on the idea of interaction of cultures in multicultural society and the necessity of acquisition of not only a language system, but also a conceptual system in the process of language teacher education so that future teachers should know how to use these techniques in their classroom activities for the purpose of preparing their students to the positive interaction and peaceful life in multicultural world.

The following methods were used in our research: 1) student interviewing before and after experimental teaching; 2) direct observation during experimental teaching; 3) experimental teaching; 4) data analysis.

In order to evaluate the development of polycultural competence the experimental teaching was held. There were organized two groups of students at the department of foreign languages in Kemerovo state university: the control group - the classes in which were given in regular way (100 students), and the experimental group (75 students).

In order to evaluate the development of polycultural competence the experiment was held. There were organized two groups of students at the department of foreign languages in Kemerovo state university: the control group - the classes in which were given in regular way (154 students), and the experimental group (100 students). There were created four stages for realization of the new system of teacher training (see Table 1).

Table 1. Stages for competence development

\begin{tabular}{|l|l|l|l|}
\hline Stages & Competences & Means & $\begin{array}{l}\text { Types of } \\
\text { exercises on }\end{array}$ \\
\hline 1. Preparetory & $\begin{array}{l}\text { Communicational- } \\
\text { technological, } \\
\text { polylinguistic }\end{array}$ & $\begin{array}{l}\text { Internet } \\
\text { resources, } \\
\text { language }\end{array}$ & $\begin{array}{l}\text { Exercises on } \\
\text { technological } \\
\text { and linguistic } \\
\text { features of } \\
\text { Internet }\end{array}$ \\
\hline 2. Interaction & $\begin{array}{l}\text { Polyconceptual, } \\
\text { polylinguistic }\end{array}$ & Dictionaries & $\begin{array}{l}\text { Lexical } \\
\text { presentation of } \\
\text { concept }\end{array}$ \\
\hline $\begin{array}{l}\text { 3.Individual } \\
\text { Investigation }\end{array}$ & All competences & $\begin{array}{l}\text { Web-sites, } \\
\text { forums, } \\
\text { chats }\end{array}$ & $\begin{array}{l}\text { Contextual } \\
\text { presentation of } \\
\text { concept }\end{array}$ \\
\hline $\begin{array}{l}\text { 4. Creative } \\
\text { presentation }\end{array}$ & All competences & $\begin{array}{l}\text { Oral } \\
\text { presentation }\end{array}$ & $\begin{array}{l}\text { Essay- } \\
\text { investigation }\end{array}$ \\
\hline
\end{tabular}

The results were evaluated on the bases of the final essays-investigations. In order to evaluate such type of the competence as polyconceptual, the following skills were analyzed: the skill to define the universal cultural concepts, typical for the cultures in contact; the skill to define specific ethnocultural content of the universal concepts.

In order to evaluate the polylinguistic competence such skills were taken into account as: the skill to define cultural characteristics of the communication partner and transfer his own culture with the help of the English language as an international one; the skill to underline cultural features of the communication partner on the bases of his native language.

Communicational-technological competence was evaluated according to the capability to use the Internet resources for the purpose of searching for necessary information and creating interaction with representatives of different cultures.

Three levels of the development were defined: high, medium, low. The students of the experimental group demonstrated only high and medium level of polycultural competence development. These results proved the effectiveness of our system for foreign language teacher training.

\section{References}

[1] Bennet M.J. Towards Ethnorelativism: A Developmental Model of Intercultural Sensitivity// Education for the Intercultural Experience/ Paige R.M. (ed.). U.S.A.: Intercultural Press, 1993. P. 21-71.

[2] Lusting M.W., Koester J. Intercultural competence. Interpersonal communication across cultures. - Longman, 1999. $401 \mathrm{p}$.

[3] Kubryakova,E. Dictionary of cognitive terms.-M., 1996.- 245 p.

[4] Likhachev,D. Conceptual sphere of the Russia language. - M.: Academia, 1997. P. 280- 287.

[5] Crystal, D. Language and the Internet. Cambridge, 2001. $272 \mathrm{p}$ 